\title{
Benign Placental Neoplasm
}

National Cancer Institute

\section{Source}

National Cancer Institute. Benign Placental Neoplasm. NCI Thesaurus. Code C8545.

A non-metastasizing neoplasm that arises from the placenta. Representative examples include hemangioma and polyp. 